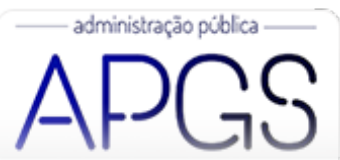

Administração Pública e Gestão Social ISSN: 2175-5787

apgs@ufv.br

Universidade Federal de Viçosa

Brasil

\title{
Assédio Moral na Pós-Graduação: Práticas e Elementos Culturais Propiciadores
}

Soares Nunes, Thiago

Assédio Moral na Pós-Graduação: Práticas e Elementos Culturais Propiciadores

Administração Pública e Gestão Social, vol. 14, núm. 1, 2022

Universidade Federal de Viçosa, Brasil

Disponible en: https://www.redalyc.org/articulo.oa?id=351569604009

\section{(c) $(1) \Theta$}

Esta obra está bajo una Licencia Creative Commons Atribución-NoComercial-SinDerivar 4.0 Internacional. 


\title{
Assédio Moral na Pós-Graduação: Práticas e Elementos Culturais Propiciadores
}

\author{
Postgraduate Bullying: Enabling Cultural Elements and Practices \\ Acoso Moral en el Postgrado: Prácticas y Elementos Culturales Propiciadores
}

Thiago Soares Nunes

Universidade FUMEC, Brasil

Redalyc: https://www.redalyc.org/articulo.oa?

adm.thiagosn@gmail.com

$\mathrm{id}=351569604009$

Recepción: 22 Mayo 2021

Aprobación: 09 Septiembre 2021

Publicación: 07 Enero 2022

\section{Resumo:}

Objetivo da pesquisa: caracterizar os elementos presentes na cultura da Pós-Graduação identificados como favoráveis à ocorrência do assédio moral, tendo como base os discursos de docentes e discentes vinculados aos Programas de Pós-Graduação stricto sensu de uma Universidade Pública.

Enquadramento teórico: assédio moral, cultura organizacional e brasileira.

Metodologia: a pesquisa foi caracterizada como qualitativa, descritiva e estudo de caso, com participação de 126 respondentes do questionário online e a realização de sete entrevistas. Para o tratamento dos dados, utilizou-se a análise de conteúdo e a estatística descritiva.

Resultados: constatou-se que os participantes acreditam que a cultura da Pós-Graduação pode influenciar a manifestação do assédio moral. Dessa forma, mediante constatação de suas verbalizações, foram identificados elementos que favorecem sua ocorrência: impunidade; questões grupais; cobranças e pressões; produtividade; competitividade e vaidade. Tais elementos são manifestados, muitas vezes, pelo abuso de poder e recusa da diferença. Portanto, é preciso rever as práticas e comportamentos dentro da Pós-Graduação para evitar que situações de assédio e outras violências ocorram.

Originalidade: preenche-se uma lacuna quanto a identificar quais são os elementos culturais que podem favorecer a manifestação do assédio moral no ambiente da Pós-Graduação. Embora discutido que a cultura pode influenciar na ocorrência, existe esse gap em que as pesquisas e literatura não apresentam quais são.

Contribuições teóricas e práticas: além da contribuição científica na construção do conhecimento, discutir os elementos culturais que podem favorecer ao assédio moral possibilita, a partir desses, contribuir para que sejam desenvolvidas açôes e políticas com foco em amenizar a sua incidência, prevenir e combatê-la. Bem como debater e divulgar uma temática considerada um tabu em muitos espaços organizacionais.

PalaVras-chaVe: Assédio Moral, Cultura Organizacional, Universidade, Pós-Graduação.

\section{ABstRACT:}

Research objective: characterize the elements present in the culture of Postgraduate identified as favorable to the occurrence of workplace bullying, based on the speeches of teachers and students linked to the Postgraduate Programs strictosensu of a Public University.

Theoretical framework: workplace bullying, organizational and brazilian culture.

Methodology: the research was characterized as qualitative, descriptive and case study, with the participation of 126 respondents to the survey and seven interviews - with content analysis and descriptive statistics.

Results: it was found that the participants believe that the culture of Postgraduate can influence the manifestation of workplace bullying. Thus, upon verification of their verbalizations, elements that enabling their occurrence were identified: impunity; group issues; collections and pressures; productivity; competitiveness and vanity. Such elements are often manifested by the abuse of power and the refusal of difference. Therefore, it is necessary to review the practices and behaviors within the Postgraduate Program's to prevent situations of workplace bullying and other violence from occurring.

Originality: a gap is filled in as to identify which are the cultural elements that can facilitate the occurrence of workplace bullying in the postgraduate environment. Although it is argued that culture can influence the occurrence, there is this gap in which research and literature do not present what those elements are.

Theoretical and practical contributions: in addition to the scientific contribution to the construction of knowledge, discussing the cultural elements that can facilitate workplace bullying makes it possible, from these, to contribute to the development of 
actions and policies to mitigate their incidence, prevent and combat it. As well as, to debate and publicize a theme considered as a taboo in many organizational spaces.

KEYWORDs: Workplace Bullying, Organizational Culture, University, Postgraduate.

\section{RESUMEN:}

Objetivo de la investigación: caracterizar los elementos presentes en la cultura del postgrado identificados como favorables a la ocurrencia del acoso moral, a partir de los discursos de docentes y estudiantes vinculados a los Programas de Posgrado stricto sensu de una Universidad Pública.

Marco teórico: acoso moral, cultura organizacional y brasileña.

Metodología: la investigación se caracterizó como cualitativa, descriptiva y estudio de caso, con la participación de 126 personas que respondieron al cuestionario online y siete entrevistas - con análisis de contenido y estadística descriptiva.

Resultados: Se encontró que los participantes creen que la cultura de la posgraduación puede influenciar en la manifestación del acoso moral. Así, al verificar sus verbalizaciones, se identificaron elementos que favorecen su ocurrencia: impunidad; cuestiones de grupo; cargos y presiones; productividad; competitividad y vanidad. Estos elementos se manifiestan, muchas veces, por el abuso de poder y el rechazo de la diferencia. Por lo tanto, es necesario revisar las prácticas y comportamientos dentro del Programas de Postgrado para evitar que ocurran situaciones de acoso y otras violencias.

Originalidad: se llena una brecha para identificar cuáles son los elementos culturales que pueden favorecer la manifestación del acoso moral en el ámbito del postgrado. Aunque se argumenta que la cultura puede influir en la ocurrencia, existe esta brecha en la que no se presentan investigaciones y literatura que son.

Aportes teóricos y prácticos: además del aporte científico a la construcción del conocimiento, discutir los elementos culturales que pueden favorecer el acoso moral permite, a partir de estos, contribuir al desarrollo de acciones y políticas para mitigar su incidencia, prevenirlo y combatirlo. Así como, debatir y dar a conocer un tema considerado tabú en muchos espacios organizacionales.

Palabras clave: Acoso Moral, Cultura Organizacional, Universidad, Postgrado.

\section{INTRODUÇÃO}

As organizações públicas, consideradas como sistemas dinâmicos, complexos, interdependentes e interrelacionados coerentemente, têm por objetivo prestar serviços e cumprir compromissos com a sociedade (Pires \& Macêdo, 2006). Essas organizações cumprem suas funções e serviços buscando uma maior eficiência da "máquina pública" e seguem, como muitas organizações, princípios da administração científica com vistas à produtividade (Tolfo \& Nunes, 2017). As organizações públicas apresentam características básicas, como a elevada burocracia existente no seu funcionamento, apego às regras e rotinas, supervalorização das hierarquias, paternalismo nas relações, apego ao poder, entre outras (Pires \& Macêdo, 2006).

Ao adentrar nesse tipo de organização e focalizar nas Universidades - Pós-Graduação, lócus da investigação -, é possível também visualizar essas características presentes nas práticas e na estrutura das universitárias públicas. As Universidades/Pós-Graduação sofrem pressão e são influenciadas pela sociedade, pelo mercado, pelo Estado, que provocam mudanças nas suas práticas e, consequentemente, modificam a sua cultura. Podese enfatizar que a atual conjuntura das Universidades/Pós-Graduação se encontra cada vez mais turbulenta e reflete muitos problemas da própria sociedade e das organizações.

O mundo da academia, mesmo após diversas mudanças, não é diferente do mundo das fábricas. É um ambiente de discursos e promessas, de competição e exigências, favorecimento de grupos e conflitos, que reorganiza a produção acadêmica com vistas a uma maior produtividade (Nunes, 2016). As exigências ao corpo docente e discente se intensificam e atingem níveis elevados e, concomitantemente, as relações interpessoais vão se precarizando.

Esses elementos supracitados estão presentes e arraigados na própria cultura e práticas na Pós-Graduação, os quais podem proporcionar práticas e comportamentos desrespeitosos, antiéticos, violentos e que, em determinados contextos e de forma repetida e duradoura, se transformam em assédio moral. Em outros termos, entende-se que algumas práticas e elementos culturais presentes na Pós-Graduação são favoráveis para a manifestação de violências, inclusive, o assédio moral. 
O assédio moral se configura como condutas abusivas (gestos, comportamentos, atitudes e palavras), repetidas e duradouras, que atente contra a dignidade ou integridade de um indivíduo, podendo ameaçar seu trabalho ou degradar o ambiente laboral (Hirigoyen, 2006). O ambiente universitário/educação é um dos mais afetados pelas práticas de assédio moral (Hirigoyen, 2006), haja vista, principalmente, à recusa de diferenças e o abuso de poder (Nunes \& Tolfo, 2015; Nunes, 2016).

Partindo das reflexóes apresentadas, este artigo objetiva caracterizar os elementos presentes na cultura da Pós-Graduação identificados como favoráveis à ocorrência do assédio moral, tendo como base os discursos de docentes e discentes vinculados aos Programas de Pós-Graduação stricto sensu de uma Universidade Pública. Portanto, esta pesquisa apresentará somente essa relação (cultura e assédio), não apresentando informações sobre a caracterização da cultura da Pós-Graduação ou sobre o assédio moral.

A contribuição deste trabalho vai além da confirmação da ocorrência de assédio moral dentro do ambiente da Pós-Graduação, outrossim, confirma a existência de elementos e práticas culturais que favorecem a sua ocorrência. $\mathrm{O}$ assédio moral é um tema raramente discutido dentro das Universidades, uma vez que demonstra, muitas vezes, a ineficácia dos gestores e da organização no desenvolvimento de medidas de prevenção, intervenção e combate a essa violência. Portanto, apresentar os elementos que são presentes na sua própria cultura esclarece ainda mais o quanto é fundamental debater sobre a temática e suas relações. Além disso, possibilita desenvolver estratégias para minimizar e/ou erradicar determinadas práticas e comportamentos que influenciam sua manifestação ou que proporcionam hostilidades dentro do ambiente da Pós-Graduação.

Este artigo está estruturado em cinco seções, a contar desta introdução. A seção seguinte trata do referencial teórico, majoritariamente sobre assédio moral. Em seguida, é exposto o método utilizado para o desenvolvimento desta pesquisa. A quarta seção se refere à análise dos resultados e, por último, são apresentadas as considerações finais.

\section{ASSÉDIO MORAL E A PÓS-GRADUAÇÃO}

O tema assédio moral ganhou destaque nas últimas décadas, decorrente da intensificação e degradação das condições do trabalho, da alta competitividade e pela busca desenfreada pela produtividade a qualquer custo (Heloani \& Barreto, 2018; Nunes \& Torga, 2020). Em decorrência dessas situações, cada vez mais os trabalhadores procuram lutar contra as hostilidades que são manifestadas dentro do ambiente laboral, público e privado.

Neste artigo, tem-se por base o conceito de Heloani e Barreto (2018, p. 53), pesquisadores de grande renome no tema que, além de desenvolverem pesquisas e trabalhos sobre a temática, atuam na prevenção, intervenção e combate, destacando-se no campo latino-americano. Os autores definiram o assédio moral como:

[...] uma conduta abusiva, intencional, frequente e repetida, que ocorre no meio ambiente laboral, cuja causalidade se relaciona com as formas de organizar o trabalho e a cultura organizacional, que visa humilhar e desqualificar um indivíduo ou um grupo, degradando as suas condições de trabalho, atingindo a sua dignidade e colocando em risco a sua integridade pessoal e profissional. (Heloani \& Barreto, 2018, p. 53).

É importante ressaltar que o assédio moral é: uma prática repetida e frequente (uma situação isolada não é considerada como assédio moral, embora possa ser violenta); pode existir a intencionalidade, seja da prática hostil e/ou o desejo de causar dano a outrem; ser direcionado para um indivíduo ou um coletivo; e que existe um desequilíbrio de poder, seja hierárquico, de conhecimento, status, acesso a recursos/pessoas e demais (Ågotnes, Einarsen, Hetland, \& Skogstad, 2018; Einarsen, Hoel, Zapf, \& Cooper, 2020; Nunes, 2016;).

O assédio moral, muitas vezes, trata-se de um processo disciplinador no qual se busca anular a vontade daquele que, para o agressor, se apresenta como uma ameaça (Einarsen, Mykletun, Einarsen, Skogstad, \& 
Salin, 2017; Einarsen et al., 2020; Freitas, Heloani, \& Barreto, 2008). As práticas hostis são manifestadas, principalmente, pelo abuso de poder executado pelos superiores hierárquicos (chefes) para com seus subordinados, e pela recusa de uma diferença ou particularidade do indivíduo, que compreende questões de gênero, orientação sexual, motivos raciais ou religiosos, discriminação, deficiências ou doenças, ideologias e demais (Hirigoyen, 2006). Assim sendo, a sua incidência pode ser motivada por algum desses aspectos.

As consequências do assédio moral não são leves, seus efeitos podem ser destrutivos para as vítimas e, em casos extremos, levá-las ao suicídio (Barreto \& Venco, 2011; Heloani, 2011; Nunes \& Torga, 2020). Para os autores, é fundamental que a sociedade, as instituições, os gestores e os trabalhadores tenham consciência que os efeitos dessa violência são devastadores e repercutem em todas as esferas - indivíduo, trabalho, relacionamentos e família. O dano mais profundo, segundo Quiñones, Cantera e Moré (2013), está relacionado à construção da identidade do indivíduo, pois, ao longo da vivência de situações hostis, a vítima vai significando de modo negativo sua identidade e, por consequência, a imagem que ela tem de si mesma.

Para uma melhor compreensão da complexidade na qual se configura o assédio moral, deve-se entender que ele é um processo dinâmico e, por esse motivo, a ação e a reação devem ser compreendidas no seu contexto social e cultural (Einarsen et al., 2020; Salin \& Hoel, 2020). Pelo assédio moral ocorrer no ambiente laboral, a organização é corresponsável pela sua prática ou inibição desse comportamento (Freitas et al., 2008; Einarsen et al., 2020; Nunes, Tolfo, \& Espinosa, 2019). Ao considerar o assédio como uma questão organizacional, observa-se que algumas organizações ignoram os elementos propiciadores da violência, ou seja, ocorre porque frequentemente os gestores se omitem (Ågotnes et al., 2018; Nunes et al., 2019).

Ao observar algumas estruturas organizacionais, em especial as Universidades, lócus deste estudo, em pesquisa realizada por Buendía (2003) em universidades espanholas, foi identificado que a universidade é um forte elemento estressante devido a sua estrutura organizacional - obsoleta, rígida, altamente burocratizada, abusos de poder -, além de um sistema de corporativismo e impunidade, gerando vantagens para uns e punições para os que estão fora do grupo dominante. Em outras palavras, um ambiente que apresenta "solo fértil" para a ocorrência de assédio moral.

$\mathrm{Na}$ realidade brasileira, em pesquisa realizada por Nunes (2016), identificou-se a existência de alguns elementos que favorecem e/ou sustentam as práticas culturais de assédio moral em uma Universidade Federal: a impunidade ou a falta de punição para assediadores; as diferenças entre as categorias docente e técnico, entre novos e antigos, entre efetivos e substitutos; a política e grupos dominantes de poder; a falta de preparo para os servidores executarem suas atividades e para ocuparem cargos de chefia; as ambiguidades no que se refere às incertezas do trabalhador em relação a sua atividade e expectativas laborais; e o distanciamento entre o discurso e a prática, principalmente dos gestores, os quais deveriam inibir todas essas situações recorrentes na organização.

Constatou-se, ainda, que a cultura e as práticas organizacionais na Universidade são reprodutoras, na maioria das vezes, de uma cultura mais ampla, possuindo elementos presentes na cultura do serviço público e na cultura brasileira (Nunes, 2016). Observa-se uma relação frequente de elementos da própria cultura da organização e cultura externa (nacional) que podem influenciar a manifestação do assédio moral.

A cultura nacional, brasileira, apresenta alguns pontos críticos: a flexibilidade; o formalismo; a lealdade às pessoas; o paternalismo; e a impunidade que garante o desempenho desse sistema (Alcadipani \& Crubellate, 2003; Prates \& Barros, 1997). Por sua vez, as organizações públicas apresentam traços culturais característicos e presentes na cultura nacional, como por exemplo: apego às rotinas e regras; supervalorização da hierarquia; paternalismo nas relações; apego ao poder; apadrinhamento político; relações de favorecimento pessoal; privilégios que contornam as normas formalmente instituídas; sentimento de iniquidade e injustiça; incongruências entre o discurso e as práticas oficiais (Pires \& Macêdo, 2006; Tolfo \& Nunes, 2017).

No que concerne aos Programas de Pós-Graduação, visualiza-se algumas práticas culturais já arraigadas e perpetradas/ensinadas, como a cultura do produtivismo acadêmico, que gera pessoas com uma mentalidade instrumental agressiva e competitividade exacerbada. No Brasil, a produção acadêmica virou sinônimo de 
fazer pontos, cuja lógica consiste em produzir, elaborar artigos para periódicos bem avaliados e organizar capítulos ou livros científicos em quantidade e qualidade (certificado pelo Qualis/CAPES) para alcançar maior destaque/nível (Alcadipani, 2011, 2017; Leite, 2017; Martins \& Lucena, 2014).

Enquanto a cultura da competição e da produtividade acadêmica consistirem em valores fundamentais, tanto docentes quanto discentes buscarão diferenciação frente aos poucos recursos existentes. Ou seja, o atual modelo de produtividade e pontuação - "publicar ou perecer" - perpetrado pela CAPES enquanto uma indicação dos organismos multilaterais que, consequentemente, seguem a lógica do capitalismo de transformar a educação em mercadoria, proporcionam uma "guerra" (Nunes, 2016).

Influenciado pelos aspectos culturais e pelo próprio sistema a qual a Pós-Graduação se relaciona, a Figura 1 ilustra essa relação entre o indivíduo, a organização e a cultura.

Figura 1: Relações entre assédio moral, organização e cultura.



Fonte: Elaborado pelo autor.

Por fim, a lógica dessa ilustração vai ao encontro do que Einarsen et al. (2020), Heloani e Barreto (2018), Notelaers, Heijden, Hoel e Einarsen (2018), Nunes (2016), Salin (2003) e outros pesquisadores têm ressaltado/pesquisado nos últimos anos - o assédio moral. Além da questão interpessoal (relação entre vítima e agressor), encontra-se, muitas vezes, nas estratégias de gestão arraigadas na cultura organizacional e nas práticas e valores regionais/nacionais. Por meio dessas discussões é que o assédio moral pode ser realmente compreendido, prevenido e combatido.

\section{MÉTODO}

A pesquisa apresentou uma abordagem qualitativa e buscou compreender os significados, os motivos e os valores que os indivíduos dão a determinado fenômeno e suas experiências nele vividas (Creswell, 2014). A utilização da abordagem qualitativa se justifica devido ao interessante em entender e aprofundar os significados e experiências que os participantes tiveram em relação aos temas abordados durante a pesquisa (cultura organizacional da Pós-Graduação e o assédio moral), bem como os procedimentos adotados na coleta e na análise dos dados. Ademais, o trabalho se configura como um estudo de caso, que objetivou aprofundar a descrição e o conhecimento de determinada realidade e, a partir disto, formular proposições para o estudo em outras localidades (Triviños, 1992). A pesquisa ocorreu nos Programas de Pós-Graduação (PPG’s) stricto sensu de uma Universidade Pública.

Os participantes foram os docentes (aproximadamente 660) e discentes de mestrado e doutorado (aproximadamente 2.312). Optou-se por não definir uma amostra nesta pesquisa, uma vez que foi possível o acesso a todos os participantes por meio de contato com as secretarias dos PPG's para divulgação e por envio de e-mails coletados nas páginas dos programas. A pesquisa pode ser considerada censitária, pois abrange a totalidade dos componentes do universo (Marconi \& Lakatos, 2009).

Os critérios de participação na pesquisa foram se o docente ou discente estava como regular na PósGraduação e concordava em participar. Foram excluídos da pesquisa aqueles que não estavam vinculados 
como docente ou discente de algum PPG na Universidade analisada. Ressalta-se que o vínculo dos participantes (docente ou discente) não foi um critério para inclusão ou exclusão na pesquisa, uma vez que se buscou analisar o ambiente da Pós-Graduação e não de maneira específica um desses.

Os dados foram coletados em dois momentos: primeiramente, com a aplicação de um questionário online; e, na sequência, foram realizadas entrevistas individuais com os participantes que se disponibilizaram em descrever com maiores detalhes as situações vivenciadas. Ao total, foram respondidos 126 questionários e aproximadamente 20 pessoas se disponibilizaram para serem entrevistadas. Foram realizadas algumas tentativas para organizar as entrevistas, resultando, ao final, em sete entrevistados.

O questionário online apresentou perguntas abertas e fechadas, estruturado nos seguintes blocos: (1) Termo de Consentimento Livre e Esclarecido; (2) Dados Sociodemográficos e sobre o trabalho/estudo do participante na Universidade (sexo, idade, estado civil, formação, tipo de vínculo, tempo de vínculo, cargo de direção para docentes, se tem bolsa para discentes e demais); (3) Cultura e práticas na Pós-Graduação (imagem da Pós-Graduação, práticas e comportamentos predominantes, critérios de seleção de discentes, influências internas e externas, regras e normas, percepções sobre os docentes e discentes, crenças, sentidos e significados de trabalhar/estudar na Pós-Graduação e demais); (4) Assédio moral (conceituação, descrição das situações hostis, motivos da violência, características do agressor, consequências, denúncia, práticas e discursos sobre o tema e outros).

As entrevistas utilizaram um roteiro semiestruturado que aprofundou alguns dos tópicos presentes no questionário. Embora ambos os instrumentos tenham uma mesma base de perguntas, ocorreram questionamentos diferenciados para os docentes e discentes.

As informações obtidas na pesquisa possibilitaram compreender e sintetizar o objetivo proposto nesta pesquisa, que foi caracterizar os elementos presentes na cultura da Pós-Graduação que podem favorecer a ocorrência de assédio moral. Logo, o foco deste artigo é apresentar essa questão em exclusivo, não se estendendo em descrever a cultura e o assédio moral na Pós-Graduação, mas a relação entre eles.

Os dados obtidos foram analisados predominantemente pela análise de conteúdo, que convém para captar o sentido simbólico manifestado pelo participante em relação ao fenômeno com qual ele interage, por meio da interpretação de sua verbalização (Bardin, 2016). As etapas da análise seguiram as definições de Bardin (2016): organização e preparação das informações (transcrição das entrevistas e demais); leitura dos dados; codificação dos dados; classificação nas categorias de acordo com os temas trabalhados; interpretação dos significados. Inicialmente, as categorias foram construídas com base na literatura consultada e modificadas no processo de análise a partir dos relatos dos participantes, tendo como resultado: impunidade; questões grupais; cobranças e pressões; produtividade; competitividade; vaidade. Ressalta-se que foram realizadas algumas análises descritivas de frequência para as questões fechadas.

No que tange aos preceitos éticos, a pesquisa seguiu as normativas éticas apresentadas na Resolução ${ }^{\circ}$ 466, de 12 de dezembro de 2012, do Conselho Nacional de Saúde, tendo assim, a aprovação pelo Comitê Permanente de Ética em Pesquisa com Seres Humanos. Como uma forma de garantia do anonimato, os respondentes do questionário foram identificados com a letra "P" acompanhados pelos respectivos números, de 1 a 126, e os entrevistados com a letra "E", de 1 a 7.

\section{ANÁLISE E DISCUSSÃO DOS DADOS}

Antes de iniciar a apresentação das informações obtidas e analisadas, é fundamental reportar alguns dados sobre os participantes da pesquisa. A Tabela 1 apresenta as informações sobre os respondentes do questionário online; a Tabela 2, sobre os entrevistados. 
Tabela 1: Dados dos respondentes do questionário online

\begin{tabular}{|c|c|c|}
\hline QUESTIONÁRIO ONLINE(126) & FREQ, & $\%$ \\
\hline \multicolumn{3}{|l|}{ Sexo } \\
\hline Feminino & 78 & 61,9 \\
\hline Masculino & 48 & 38,1 \\
\hline \multicolumn{3}{|l|}{ Idade } \\
\hline Até 24 anos & 14 & 11,1 \\
\hline 25 a 35 anos & 69 & 54,8 \\
\hline 36 a 45 anos & 16 & 12,7 \\
\hline 46 a 55 anos & 13 & 10,3 \\
\hline Mais de 56 anos & 14 & 11,1 \\
\hline \multicolumn{3}{|l|}{ Estado civil } \\
\hline Casado(a)/Uniẫo Estável & 56 & 44,4 \\
\hline Divorciado(a)/Separado(a) & 9 & 7,1 \\
\hline Solteiro(a) & 60 & 47,6 \\
\hline Viúvo(a) & 1 & 0,8 \\
\hline \multicolumn{3}{|l|}{ Vínculo com a Pós-Graduação } \\
\hline Docente & 36 & 28,6 \\
\hline Discente de Mestrado & 49 & 38,9 \\
\hline Discente de Doutorado & 41 & 32,5 \\
\hline \multicolumn{3}{|l|}{ Centro de vínculo } \\
\hline Ciências Agrárias & 24 & 18,8 \\
\hline Ciências Biológicas & 20 & 15,6 \\
\hline Ciências da Saúde & 28 & 21,9 \\
\hline Ciências Exatas e da Terra & 9 & 7,0 \\
\hline Ciências Humanas & 20 & 15,6 \\
\hline Ciências Sociais Aplicadas & 24 & 18,8 \\
\hline Engenharias & 2 & 1,6 \\
\hline Linguística, Letras e Artes & 1 & 0,8 \\
\hline \multicolumn{3}{|c|}{ Tempo de trabalho na universidade (docentes) } \\
\hline de 1 a 5 anos & 5 & 13,9 \\
\hline de 6 a 10 anos & 7 & 19,4 \\
\hline de 11 a 15 anos & 3 & 8,3 \\
\hline de 16 a 20 anos & 2 & 5,6 \\
\hline de 21 a 25 anos & 3 & 8,3 \\
\hline mais de 25 anos & 16 & 44,4 \\
\hline \multicolumn{3}{|c|}{ Tempo de trabalho na Pós-Graduação na universidade (docentes) } \\
\hline de 1 a 5 anos & 14 & 38,9 \\
\hline de 6 a 10 anos & 4 & 11,1 \\
\hline de 11 a 15 anos & 9 & 25 \\
\hline de 21 a 25 anos & 5 & 13,9 \\
\hline mais de 25 anos & 4 & 11,1 \\
\hline \multicolumn{3}{|c|}{ Cargo de direção na Pós-Graduação (docentes) } \\
\hline Não & 28 & 77,8 \\
\hline $\operatorname{Sim}$ & 8 & 22,2 \\
\hline \multicolumn{3}{|c|}{ Tempo que cursa Pós-Graduação na universidade (discentes) } \\
\hline menos de 6 meses & 9 & 10 \\
\hline de 6 meses a 1 ano & 13 & 14,4 \\
\hline de 1 ano a 1,5 ano & 15 & 16,7 \\
\hline de 1,5 ano a 2 anos & 16 & 17,8 \\
\hline de 2,5 anos a 3 anos & 18 & 20 \\
\hline de 3,5 anos a 4 anos & 8 & 8,9 \\
\hline mais de 4 anos & 11 & 12,2 \\
\hline \multicolumn{3}{|l|}{ Bolsista (discentes) } \\
\hline Não & 34 & 37,8 \\
\hline $\operatorname{Sim}$ & 56 & 62,2 \\
\hline \multicolumn{3}{|c|}{ Obrigado a cumprir carga horária semanal (discentes) } \\
\hline Nẫo & 55 & 61,1 \\
\hline $\operatorname{Sim}$ & 35 & 38,9 \\
\hline Carga horária semanal: mínima & 4 horas & - \\
\hline Carga horária semanal: máxima & $\begin{array}{l}40 \\
\text { horas }\end{array}$ & - \\
\hline
\end{tabular}


A maior parte dos respondentes do questionário online é do sexo feminino $(61,9 \%)$, entre 25 e 35 anos $(54,8 \%)$, o que corresponde a um público mais jovem. Em sua maioria, a pesquisa foi respondida pelos discentes vinculados aos cursos de mestrado (38,9\%) e doutorado (32,5\%), sendo 62,2\% bolsistas. Com relação aos docentes, observa-se que a grande maioria $(44,4 \%)$ está na instituição há mais de 25 anos, e 38,9\% são recentes na Pós-Graduação, entre 1 e 5 anos.

No questionário online, uma das perguntas finais convidava o participante a ser entrevistado para fornecer maiores detalhes sobre sua vivência, sendo realizada sete entrevistas. A Tabela 2 apresenta alguns dados sobre os entrevistados.

Tabela 2: Dados dos entrevistados

\begin{tabular}{|cccccc|}
\hline n. & Sexo & Típo de Vínculo & Tempo na Pós-Grad. & Direção na Pós-Grad. & Bolsista \\
\hline 1 & Feminino & Docente & de 6 a 10 anos & Não & - \\
2 & Masculino & Discente de Doutorado & de 3,5 a 4 anos & - & Não \\
3 & Feminino & Discente de Mestrado & de 1 a 1,5 ano & - & Não \\
4 & Feminino & Docente & +25 anos & Não & - \\
5 & Feminino & Discente de Doutorado & de 2,5 a 3 anos & - & Sim \\
6 & Masculino & Discente de Doutorado & de 1,5 a 2 anos & - & Sim \\
7 & Feminino & Discente de Mestrado & de 1,5 a 2 anos & - & Sim \\
\hline
\end{tabular}

A maior parte dos entrevistados é composta por mulheres, aspecto considerado comum, segundo Nunes (2016), pois os homens se sentem com vergonha de expor sobre as situações hostis vivenciadas. Outro elemento a se destacar é a experiência de E4 na Pós-Graduação como professora e coordenadora (em período anterior à pesquisa), se comparada com os outros entrevistados.

O primeiro questionamento realizado aos participantes foi se a cultura presente na Pós-Graduação pode influenciar o surgimento de casos de assédio moral. Foi afirmado por $72,2 \%$ dos participantes que a cultura presente na Pós-Graduação pode influenciar na ocorrência de assédio moral, 20\% falaram que não sabem e $9 \%$ que não influencia.

A Pós-Graduação e seus colaboradores, discentes e principalmente docentes, são influenciados e influenciadores das práticas e cultura nesse ambiente. A Pós-Graduação apresenta características de alta competitividade, disputas de ego e vaidade, filosofias de "publicar ou perecer" (Alcadipani, 2011; Martins \& Lucena, 2014; Nunes \& Tolfo, 2020), relações abusivas de poder e outros comportamentos que fogem dos princípios éticos (Nunes, 2016). Pelas características elencadas, esses traços culturais presentes na PósGraduação podem favorecer e influenciar situações de assédio moral nesse ambiente.

As próximas subseções apresentam os elementos resultantes da relação entre a cultura da pós-graduação e o assédio moral, frequentemente mencionados pelos participantes e identificados nas suas verbalizações como influenciadores da ocorrência do assédio moral, a saber: impunidade; questões grupais; cobranças e pressões; produtividade; competitividade e vaidade. Ressalta-se que esses elementos não são encontrados exclusivamente nesse ambiente, estando presentes em muitas outras organizações, públicas ou privadas.

\subsection{Impunidade}

O aspecto com maior relevância na pesquisa é a impunidade, a falta de punição, seja com relação ao assédio moral ou outras práticas e comportamentos antiéticos e violentos. Segundo diversos participantes, "a certeza de impunidade” (P78) é um dos fatores que mais influenciam a ocorrência do assédio moral na PósGraduação. A impunidade é uma das características presente no ambiente organizacional público e privado e é um traço da cultura brasileira (Nunes, 2016; Nunes et al., 2019). 
Em questionamento feito aos docentes sobre a existência de punição quando ocorre a violação do código de ética ou dos limites aceitáveis de comportamento, 50\% afirmaram que nunca ou raramente isso ocorre. Ao serem questionados sobre o porquê de não ocorrer, grande parte relata sobre o corporativismo existente na instituição, principalmente, no que se refere ao grupo dominante; no caso da Pós-Graduação, os docentes (dependendo a que grupo ele está vinculado). Para ilustrar o exposto, a impunidade ocorre quando há "o coleguismo, de um professor com outro, ele vê o que acontece, mas fica quieto e não faz nada, não ajuda o aluno. Não existe uma medida do programa para isso, não existe professor preocupado com aluno" (E5).

Para Alcadipani e Crubellate (2003) e Prates e Barros (1997), a impunidade, traço importante da cultura brasileira, é o elemento que fecha e alimenta uma cadeia de valores culturais. Para os autores, ao não punir determinado indivíduo pela sua transgressão, o gestor responsável fortalece a sua posição de poder, e pode aumentar, ao longo do subsistema institucional, traços de paternalismo, personalismo, corporativismo.

Com a certeza da impunidade, o ambiente torna-se fértil para continuar as práticas hostis contra colegas, subordinados, superiores, enfim, com aqueles que são um desafeto do agressor (Beale, 2011; Nunes et al., 2019). No caso entre docentes e discentes, principalmente aqueles que têm determinado poder, apresentam maiores possibilidades de ação sem limites e controle. Para os autores, quando não há uma punição, existe nas entrelinhas uma permissividade para agir e se comportar sem se preocupar, a qual é muitas vezes vinculada ao grupo que o perpetrador está vinculado, ou seja, a impunidade pode ser um elemento existente dependendo do grupo que o indivíduo faz parte.

\subsection{Questões grupais}

As questões grupais são elementos que podem favorecer e/ou sustentar situações de assédio moral. Nesse sentido, a depender de como o indivíduo está vinculado na Pós-Graduação (discente ou docente) ou se faz parte do grupo dominante, pode influenciar na ocorrência do assédio moral ou até mesmo na sua impunidade.

$\mathrm{Na}$ própria relação entre docente ou orientador e discente ou orientando já existe uma desigualdade de poder, a qual "possibilita" atos hostis e abuso de poder por parte do professorado. Algumas verbalizações auxiliam no entendimento dessa categoria: "A hierarquia, nós alunos estamos submetidos a toda e qualquer exigência dos professores, pois precisamos" (P86); "Vejo alguns colegas relatando que o orientador ou pessoas que estão 'acima' abusam do poder” (P112);

A gente fica muito vulnerável a pessoa que "comanda". Essa pessoa pode mexer os pauzinhos dela [....] Eles têm muito poder em cima da gente, e se eles quiserem fazer alguma coisa, eles têm como. É a hierarquia né, a gente sabe quem manda. Para gente ficou bem claro, pelo menos para mim e com o pessoal que conversava, que a gente só vai pesquisar o que a gente gosta, fazer o que a gente gosta, tomar as decisões de pesquisa, quando ser doutores e tivermos nosso grupo de pesquisa. (E3).

A relação que muitas vezes ocorre é da submissão do discente ao docente que, necessariamente, depende do comportamento individual (ética, valores), "o poder de decisão dos orientadores, a depender de seu caráter, isso pode ser um fator que propicie ao assédio moral” (P71).

Com relação aos grupos dominantes que ditam as normas e a regra do jogo de maneira informal, se o indivíduo, principalmente docente, não faz parte dele, ele pode ser prejudicado (Nunes, 2016). Em outros termos, "Se alguém não faz parte da panela, é prejudicado. Há uma cultura generalizada de dois pesos, duas medidas. Se é para alguém do grupo, pode; se não é do grupo, não pode. Os regulamentos são cumpridos em termos" (P17).

É fundamental compreender que o ambiente organizacional, influenciado pelas suas classes e relações sociais, apresenta condições de dominação e de subordinação (Clegg, 1996; Heloani \& Barreto, 2018; Freitas et al., 2008). As organizações são espaços de controle, das relações de poder, a partir das quais muitas vezes ocorre o abuso de poder e, consequentemente, o assédio moral (Einarsen et al., 2020; Heloani \& Barreto, 2018; Nunes, 2016). As estratégias dos grupos dominantes não compreendem apenas punir e proibir, mas 
sim, desejam reforçar a obediência por práticas explicitas (autoridade, regras/normas, controle hierárquico) e implícitas (controlar comportamentos e deveres dos indivíduos e grupos) (Clegg, 1996; Tolfo \& Nunes, 2017).

\subsection{Cobrança e Pressão}

As cobranças e pressão manifestadas de forma exacerbada, muitas vezes hostil, podem favorecer a ocorrência do assédio moral. A cobrança se relaciona com o desenvolvimento do trabalho (dissertação, tese, publicações e demais) e a pressão com relação às datas de entregas, uma vez que os prazos são limitados e fazem parte do processo da Pós-Graduação para os docentes e discentes. No entanto, a forma como são exercidas podem incitar a ocorrência da violência.

Acho que vem dessa cobrança das coisas que a gente tem que fazer, isso desencadeia a questão do assédio. Essa cobrança exacerbada de muita coisa que não precisava, de fazer a gente parecer que não é capaz de fazer as coisas. [...] E aqui, no começo eu até me assustei. Só que tudo que a gente vai fazer a gente cobrado por isso, e não só a gente, o programa também é avaliado por isso. Pode ser que isso desencadeia, essa pressão de que a gente tem que fazer. Mas não é só na pós-graduação, isso está presente em vários lugares. (E7).

A verbalização anterior ressalta a relação entre docente, discente e programa de Pós-Graduação, as cobranças e pressões que iniciam pela CAPES, MEC e outros órgãos de fomento para os PPG's, que recai nos docentes e segue para os discentes. São aspectos presentes em todos níveis e direções, da mesma forma que no "mundo das fábricas". Como a avaliação dos PPG's depende do desempenho individual, "há certa cobrança entre pares que pode, às vezes, tornar-se desrespeitosa e gerar tensões" (P13). Com base em outro participante, "a pressão sofrida em todas as esferas faz com que a cobrança e o alto nível de estresse seja cada dia pior e casos de assédio se torne uma prática comum" (P70).

A cobrança e a pressão presentes nesta pesquisa são as mesmas exercidas no ambiente fora da academia. Cada vez mais o indivíduo exige melhores condições de trabalho, ambientes saudáveis, tratamentos respeitosos, valores e princípios éticos, contudo, o comportamento cultural e do mercado, é a cobrança e a pressão exacerbada por resultados, além de um clima de competição (Freitas et al., 2008; Heloani \& Barreto, 2018; Nunes \& Tolfo, 2017).

\subsection{Produtividade}

Alinhado às cobranças e pressões está a produtividade, característica altamente presente na Pós-Graduação, uma vez que docentes e discentes precisam publicar para se manterem no Programa ou para receberem seu título. Portanto, a cobrança para produzir é uma prática frequente em qualquer PPG, tal qual exposto pelo participante: "Existe uma cultura do produtivismo. Quem não adere à essa cultura, está fora do sistema” (P2).

Ao questionar os participantes se têm conhecimento sobre o termo publish orperish (publicar ou perecer), cerca da metade (46,3\%) não conhecia o termo. A lógica do publish or perish está na pressão constante para que os integrantes do meio acadêmico publiquem de modo frequente e rápido, principalmente em periódicos, para que assim, consigam algum status e aumentem a avaliação do PPG (Alcadipani, 2017; Leite, 2017).

Contudo, essa nocividade do termo pode refletir na saúde, na intensidade e na qualidade do trabalho (Alcadipani, 2017; Nunes \& Torga, 2020), além do que "isso gira a roda da opressão na relação docente/ discente, IES/docente" (P113) e entre MEC/CAPES e IES. Compreende-se, portanto, que "A busca excessiva pela produtividade a todo o custo pode causar comportamentos que se classifiquem como assédio moral" (P92). 
A cultura da pós-graduação influencia na ocorrência do assédio moral quando o professor tem na ideia deles que a coerção é a melhor forma com que o aluno produza, porque eles acham que pela dor o aluno vai poder produzir mais. A CAPES exige, e os professores acham que tem que produzir, e acham que a única forma de produzir é coagindo o aluno. (E5).

Para Alcadipani (2011, p. 1176) "o produtivismo acadêmico impera. Viramos gestores de projetos, burocratas de papers. A formação vem sendo cada vez mais esquecida, o objetivo é produzir, ainda que sem formação ou conteúdo. Muitos estão adoecendo com este sistema”. Para o autor, as explicações do produtivismo seriam o gerencialismo na produção científica, má adaptação dos modelos vindo de países estrangeiros e a CAPES. No que diz respeito a CAPES, "o sistema está falido, caduco e precisa ser reformulado para valorizar a boa formação dos alunos e a produção acadêmica de qualidade" (Alcadipani, 2011, p. 1177).

Embora exista uma crítica com relação ao sistema de cobrança que é perpetrado pela CAPES e influencia os PPG's e demais, não se observa uma movimentação concreta com relação às ações mais propositivas. Em geral, as ações ficam nos discursos e, com isso, as pressões por produção permanecem ou até se intensificam devido à alta competitividade existente nesse meio.

Nesse sentido, segundo Leite (2017), a resiliência atualmente se configura como um qualificativo do indivíduo que, ao se afastar do seu trabalho, por qualquer que seja o motivo, perde oportunidades de projetos e produção que dificilmente recuperará. Permanece, dessa forma, o discurso de que o trabalhador deve cada vez mais suportar o cansaço, as pressóes e as cobranças exacerbadas, além de trabalhar de forma repetitiva e sem qualquer opção de desistir (Nunes \& Torga, 2020).

\subsection{Competitividade}

Nesse ambiente de cobranças, de pressões e de produtividade, surge também a competitividade. Embora a competitividade possa ser observada como algo positivo no campo da pesquisa para estimular a produção qualificada e melhorar o conceito dos PPG's, em geral, foi observada como negativa pelos participantes, como uma competição hostil que diminui a possibilidade de cooperação.

No ambiente da educação e da pesquisa, o assédio moral é considerado um fenômeno de sobrevivência, uma vez que poucos conseguem se destacar e ter algum reconhecimento e, com isso, provocam a inveja dos demais (Hirigoyen, 2006; Nunes \& Torga, 2020). Tais situações, por si só, possibilitam uma competitividade não saudável, que esconde ideias, materiais e equipamentos para si, sem interesse em cooperação com outros.

Em questionamento feito aos participantes com relação à competitividade nas suas mais diferentes formas, observou-se uma alta incidência, conforme pode ser visualizado na Tabela 3.

Tabela 3: Competitividade (\%)

\begin{tabular}{llllll}
\hline COMPETITIVIDADE & $\begin{array}{l}\text { MUITO } \\
\text { BAIXO }\end{array}$ & BAIXO & MÉDIO & ALTO & $\begin{array}{l}\text { MUTO } \\
\text { ALTO }\end{array}$ \\
\hline Entre discentes & 2,6 & 3,5 & 32,2 & 33 & 28,7 \\
Entre discentes antigos e novos & 4,5 & 16,2 & 36,9 & 22,5 & 19,8 \\
Entre discentes e docentes & 15,5 & 31,8 & 30,9 & 10,9 & 10,9 \\
Entre docentes & 0,9 & 6,1 & 9,6 & 29,8 & 53,5 \\
Entre docentes antigos e novos & 1,8 & 5,5 & 18,2 & 29,1 & 45,5 \\
Entre linhas de pesquisa & 4,5 & 10,7 & 17,9 & 30,4 & 36,6 \\
Entre grupos de pesquisa & 3,7 & 13 & 20,4 & 29,6 & 33,3 \\
Dentro dos grupos/núcleos de pesquisa & 5,6 & 13,9 & 26,9 & 29,6 & 24,1 \\
\hline
\end{tabular}

Existe uma elevada ocorrência em todas as categorias, com exceção entre discentes e docentes. Os valores, por si só, exemplificam a realidade da Pós-Graduação, práticas essas já inseridas na própria cultura, por exemplo, impedir que orientando(a) trabalhe ou converse com outro docente ou discente sobre sua pesquisa/ ideia com medo de que a ideia seja "roubada". 
Algumas verbalizações exemplificam esses aspectos: "a competitividade cria um clima de exigência extrema e constante; impossibilita que discentes participem de atividades com outros grupos por serem 'rivais'; gera paranoias de que o outro irá sabotá-lo" (P115); “A competitividade aumentou muito nos últimos anos, creio que incentivada, muitas vezes pelo próprio orientador. Isso gera inimizades e angústias levando a casos de depressão e abandono das atividades" (P36).

Embora exista um discurso de cooperação dentro desse ambiente, Heloani (2005) e Nunes (2016) apontam um paradoxo, existindo dois elementos que são antagônicos: a necessidade de cooperação e a competição pela aquisição ou manutenção de determinado cargo ou status. E com isso, "O individualismo é incitado pela regulação avaliativa punitiva, e às vezes, sutil, manipulatória da vaidade e instauradora de competitividade mórbida" (Silva, Heloani, \& Piolli, 2012, p. 381).

De fato, para alguns participantes, "[...] a competitividade somada ao individualismo das pessoas pode influenciar na ocorrência do assédio" (P48). Segundo Hirigoyen (2006), Freitas et al. (2008), Heloani e Barreto (2018) e Einarsen et al. (2020), ambientes altamente estressantes e competitivos, com conflitos interpessoais e falta de atmosfera amigável e solidária, podem servir de solo fértil para a incidência de assédio moral.

Por certo, a competitividade, manifestada entre docentes e/ou discentes, grupos de pesquisa, linhas e nas mais diversas formas, pode levar a uma cobrança excessiva de resultados, intensificando o trabalho (do indivíduo ou grupo) para atingir os objetivos estabelecidos a qualquer custo. Assim, a competitividade alinhada ao produtivismo proporciona, em alguns locais, um "sistema de recompensas" e rankeamento, dando destaque aos mais produtivos. E no seu extremo, "pode provocar desânimo, desmotivação, depressão em alguns casos, quando a pessoa não se sente competente para manter a produtividade exigida" (P2). Algumas práticas organizacionais relacionadas a aspectos particulares dos sistemas de recompensa e alta competição interna, também pode atuar como antecedentes do assédio moral (Salin \& Hoel, 2020).

\subsection{Vaidade}

A vaidade no âmbito acadêmico envolve indivíduos que se consideram melhores que os outros, que desejam atrair a admirações e inveja dos pares, podendo também, menosprezar os outros como forma de se engrandecer. Para alguns, o status de ser docente na Pós-Graduação, por exemplo, aqueles com maior produção e destaque, é algo que os sobrepõe em relação aos outros, principalmente, com aqueles que não estão vinculados.

A vaidade é cotidiana na pós-graduação. Se manifesta quando um docente passa o tempo todo criticando os colegas (ou seja, ele se acha melhor que os outros), quando ele acredita que os seus artigos têm mais qualidade que os trabalhos dos demais e passa a desqualificar os outros. Se manifesta também quando o docente vive a paranoia de acreditar que há riscos constantes dos outros copiarem o que ele está fazendo. (P1).

Professores que não respeitam normas, desrespeitam os alunos e se consideram donos da verdade, não aceitam ser contrariados, o que torna impossível a realização de debates saudáveis em sala. Isso nos torna máquinas de produção de provas e artigos, e impede a consolidação da aprendizagem, além de desestimular a construção de pensamento crítico. Além disso, novamente, muitos professores não dissertam sobre seus métodos de correção, o que a torna obscura. Não temos meios para pedir reavaliação, o que nos deixa nas mãos da necessidade de agir como cães dóceis que não podem contrariar seus donos. (P49).

A vaidade, conforme apresentado nas verbalizações anteriores, pode favorecer a ocorrência de assédio moral, por meio das críticas com intenção de diminuir o outro ou de impor suas ideologias, a desqualificação do trabalho ou de comportamentos, o desrespeito e humilhação, entre outras ações. São situações hostis que tem o intuito de menosprezar e constranger o alvo, dizendo que ele é incompetente e, assim, engrandecer-se perante ele e os demais (Heloani \& Barreto, 2018, Hirigoyen, 2006, Nunes, 2016). 
Para Lubit (2002), algumas pessoas podem ter traços narcísicos de personalidade, tais como egocentrismo, necessidade de ser admirado, intolerância a críticas, os quais são elementos que podem ser identificados nos agressores. Ademais, Neuman e Baron (2011) sugerem que muitos episódios de agressividade entre adultos, manifestados das mais diversas formas, têm como causa a vaidade e autoestima.

Por fim, no ambiente de competitividade e vaidade da Pós-Graduação, "brilhar mais que o mestre" e se sobressair mais que o outro, pode despertar sentimentos de inveja e outras manifestações, situação que pode ser o "motivo" para que o assédio moral ocorra (Nunes, 2016).

\section{CONSIDERAÇÕES FINAIS}

Este artigo teve por objetivo caracterizar os elementos presentes na cultura da Pós-Graduação identificados como favoráveis à ocorrência do assédio moral, tendo como base os discursos de docentes e discentes vinculados aos Programas de Pós-Graduação stricto sensu de uma Universidade Pública.

A partir das observações e verbalizações apresentadas pelos participantes, constataram-se alguns elementos constituintes da cultura da Pós-Graduação que favorecem o assédio moral. Em determinados casos, aparecerem também na própria cultura brasileira e do serviço público. Esses elementos foram: impunidade, questões grupais, cobranças e pressões, produtividade, competitividade e vaidade. Compreende-se que tais elementos são naturalizados, culturalmente aceitos, "incorporados" e perpetrados pelos docentes e discentes.

A impunidade ou falta de punição frente aqueles que cometem ações e comportamentos antiéticos e hostis, foi relatado de forma frequente pelos participantes, principalmente, quando o agressor é um docente. Nesses casos, a impunidade pode ter um aspecto também de corporativismo da classe.

As questões grupais fazem relação com a impunidade, em muitos casos. A depender se o indivíduo é discente ou docente ou se faz parte do grupo dominante, pode ter alguns benefícios, certas "liberdades" para continuar agindo de forma hostil com outrem ou até mesmo ser impune desses atos cometidos.

Na Pós-Graduação, a cobrança e a pressão são práticas comuns praticadas por todos, seja em relação ao trabalho, a elaboração de artigos, assiduidade e outros. O que precisa ser enfatizado, é a forma que isso se manifesta. As verbalizações ressaltaram que ocorrem de modo exacerbado e muitas vezes hostil, o que pode influenciar no surgimento de casos de assédio moral. Esse processo de cobranças e pressões não recai apenas nos discentes, o elo mais fraco e mais afetado, mas também, nos docentes e PPG's que precisam de produção para terem permanência na atividade e alta pontuação.

Diante desses aspectos, surge a produtividade, a competitividade e a vaidade, todos atuantes e recorrentes. $\mathrm{Na}$ Pós-Graduação não é difícil ter em mente o termo publish or perish, que se configura na pressão constante para publicação. A nocividade dessa situação não fica apenas no termo, mas sim, nas exigências para o alcance de tal. A competitividade impossibilita a cooperação, podendo gerar inimizades, angústias e vaidades. Até mesmo a negação, por parte de um orientador, para que seu discente não trabalhe com determinado docente ou grupo, pois, podem roubar a ideia ou ser um desafeto. A vaidade como elemento que favorece ao assédio, manifesta-se, principalmente, pelas críticas dos trabalhos, posicionamentos ou comportamentos dos outros, com intenção de diminuir ou desqualificar, mostrando que somente "ele" sabe o que é correto ou que sua ideologia é melhor.

Os docentes sêniores e júniores precisam compreender que determinadas ações e comportamentos não devem ser praticados seguindo a lógica de "se eu sobrevivi, eles vão sobreviver", de reproduzir todo o "sofrimento" e pressão ao qual eles passaram - como relatado pelos participantes. Essa "nova" forma de trabalho, de competitividade, de produtividade, de vaidades e demais, são severas, podem levar desde ao consumo de ansiolíticos ao suicídio (Leite, 2017). Assim, segundo a autora, enquanto o indivíduo reconhecer seus sintomas, mas tratar deles como algo normal ou até inevitável, continuará sofrendo ao longo do caminho, podendo intensificar os danos ou deixá-los irreparáveis. 
Portanto, é preciso falar em qualidade de vida, saúde mental e assédio moral na Pós-Graduação para que esse processo não seja doloso para quem passa ou permanece nesse ambiente. Embora a exposição de situações negativas dentro dos Programas de Pós-Graduação possa possibilitar mudança nessa cultura e práticas assediadoras, não é uma tarefa a curto prazo e nem um processo simples a ser desenvolvido por um ou outro. Trata-se de uma mobilização coletiva, que deve transformar a própria cultura e o sistema ao qual ela está inserida e se relaciona.

Por fim, observou-se que a Pós-Graduação não é muito diferente do mundo das fábricas, que exigem produtividade, trabalham sobre pressão e cobrança, clima de competitividade e impunidade. Na PósGraduação, importa a voracidade do "lattes(fundio)" e a “capes(talização)", pensamento que molda e influência negativamente o comportamento e práticas dos docentes e discentes, favorecendo a manifestação do assédio moral. Embora exista constantemente uma mudança do quadro de vinculados, principalmente entre os discentes, as práticas mencionadas ao longo desta pesquisa permanecem sendo reproduzidas e naturalizadas. A discussão sobre a estrutura, práticas e a saúde mental na Pós-Graduação, por exemplo, são frequentes e pouco (ou nada) se faz para resolver os problemas e situações que dela se originam. Afinal, em falas como "o importante é produzir, a saúde e os relacionamentos recuperam-se depois", é possível identificar situações já arraigadas dentro desse ambiente. Portanto, é preciso refletir e questionar, uma vez que o estar em uma Pós-Graduação não deve seguir em gerar um produto (artigo, dissertação, tese) e uma enfermidade concomitante. É preciso ir além da discussão, deve-se partir para a ação e cobranças/imposições nos sistemas que "controlam" e orientam a Pós-Graduação.

\section{REFERÊNCIAS}

Alcadipani, R. (2011). A Academia e a Fábrica de Sardinhas. Organizaçôes e Sociedade, 18(57), 345-348. Recuperado de https://periodicos.ufba.br/index.php/revistaoes/article/view/11155/8067

Alcadipani, R. (2017). Periódicos brasileiros em inglês: a mímica do publish or perish "global". RAE-Revista de Administração de Empresas, 57(4), 405-411. https://doi.org/10.1590/s0034-759020170410

Alcadipani, R., \& Crubellate, J. M. (2003). Cultura organizacional: generalizações improváveis e conceituações imprecisas. Revista de Administração de Empresas, 43(2), 64-77. https://doi.org/10.1590/S0034-7590200300 0200005

Ågotnes, K. W., Einarsen, S., Hetland, J., Skogstad, A. (2018). The moderating effect of lai ssez - faire leadership on the relationship between co - worker conflicts and new cases of workplace bullying: A true prospective design. Human Resource Management Journal, 28(special edition), 1-14. https://doi.org/10.1111/1748-8583.12200

Bardin, L. (2016). Análise de Conteúdo. São Paulo: Edições 70.

Barreto, M. Venco, S. (2011). Da Violência ao Suicídio no Trabalho. In Barreto, M., Netto, N. B., Pereira, L. B. (Org.). Do assédio moral à morte de si: significados sociais do suicídio no trabalho (pp. 221-248). 1. ed. São Paulo: Matsunaga.

Beale, D. (2011). An Industrial Relations Perspective of Workplace Bullying. In: Einarsen, S., Hoel, H., Zapf, D., Cooper, C. L. (Orgs.). Bullying and Harassment in the Workplace. Developments in Theory, Research, and Practice (pp. 283-300). 2a ed. London: Taylor Francis.

Buendía, J. (2003). El mobbing en el centro de estudios. Mobbing Opinion: Boletín de notícias sobre acoso psicológico. Recuperado de http://mobbingopinion.bpweb.net/artman/publish/article_793.shtml

Clegg, S. (1996). O poder, linguagem e ação nas organizações. In: Chanlat, J.-F. (Coord.). O indivíduo na organização: dimensões esquecidas (pp. 47-66). São Paulo: Atlas.

Creswell, J. W. (2014). Investigação qualitativa e projeto de pesquisa. escolhendo entre cinco abordagens. 3. ed. Porto Alegre: Penso. 
Einarsen, K., Mykletun, R., Einarsen, S., Skogstad, A., Salin, D. (2017). Ethical Infrastructure and Successful Handling of Workplace Bullying. Nordic journal of working life studies, 7(1), 37-54. https://doi.org/10.18291/njwls.v7i 1.81398

Einarsen, S., Hoel, H., Zapf, D., Cooper, C. L. (2020). The concept of bullying and harassment at work: the European tradition. In: Einarsen, S., Hoel, H., Zapf, D., Cooper, C. L. (Orgs.). Bullying and Harassment in the Workplace. Theory, Research and Practice (pp. 3-54). 3rd ed. London: Taylor Francis.

Freitas, M. E., Heloani, R., Barreto, M. (2008). Assédio moral no trabalho. Cengage Learning, São Paulo.

Heloani, R. (2005). Assédio moral: a dignidade violada. Aletheia, 22, 101-108.

Heloani, R. (2011). Quando alguém se mata no trabalho, o que está querendo dizer?. In Barreto, M., Netto, N. B., Pereira, L. B. (Org.). Do assédio moral à morte de si: significados sociais do suicídio no trabalho (pp. 249-274). 1. ed. São Paulo: Matsunaga.

Heloani, R. Barreto, M. (2018). Assédio moral: gestão por humilhação. Curitiba: Juruá.

Hirigoyen, M-F. (2006). Mal-estar no trabalho. redefinindo o assédio moral. 3a ed. Rio de Janeiro: Bertrand Brasil.

Leite, J. L. (2017). Publicar ou Perecer: a Esfinge do produtivismo acadêmico. Revista Katálysis, 20(2), 207-215. http s://doi.org/10.1590/1982-02592017v20n2p207

Lubit, Roy. (2002). O impacto dos gestores narcisistas nas organizações. Revista de Administração de Empresas, 42(3), 66-77. https://doi.org/10.1590/S0034-75902002000300007

Marconi, M. A. Lakatos, E. M. (2009). Metodologia do Trabalho Cientifico. 7a ed. São Paulo: Atlas.

Martins, A. A.V.Honorio, L. C. (2014). Prazer e sofrimento docente em uma instituição de ensino superior privada em Minas Gerais. Organizaçôes Sociedade, 21(68), 835-851. https://doi.org/10.1590/S1984-92302014000100005

Neuman, J. H. Baron, R. A. (2011). Social Antecedents of Bullying: A Social Interactionist Perspective. In: Einarsen, S., Hoel, H., Zapf, D., Cooper, C. L. (Orgs.). Bullying and Harassment in the Workplace. Developments in Theory, Research, and Practice (pp. 201-226). 2nd ed. London: Taylor \& Francis.

Notelaers, G., Heijden, B. V. D., Hoel, H., Einarsen, S. (2018). Measuring bullying at work with the short-negative acts questionnaire: identification of targets and criterion validity. Work \& Stress, 32, 1-18. https://doi.org/10. 1080/02678373.2018.1457736

Nunes, T. S. (2016). A influência da cultura organizacional na ocorrência do assédio moral no trabalho na Universidade Federal de Santa Catarina (Tese de doutorado). Programa de Pós-Graduação em Administração, Centro SócioEconômico, Universidade Federal de Santa Catarina - UFSC, Florianópolis, SC, Brasil.

Nunes, T. Torga, E. (2020). Workplace bullying in postgraduate courses: The consequences experienced by teachers and students of a Brazilian state university. Education Policy Analysis Archives, 28(11), 1-27. https://doi.org/1 $0.14507 /$ epaa. 28.4883

Nunes, T. S., Tolfo, S. R., Espinosa, L. M. C. (2019). A percepção de servidores universitários sobre as políticas, ações e discursos institucionais sobre o assédio moral no trabalho. Revista Organizações em Contexto, 15(29), 191-222. http://dx.doi.org/10.15603/1982-8756/roc.v15n29p191-222

Pires, J. C. S. Macêdo, K. B. (2006). Cultura organizacional em organizaçóes públicas no Brasil. Revista de Administração Pública, 40(1), 81-105. https://doi.org/10.1590/S0034-76122006000100005

Prates, M. A. S. Barros, B. T. (1997). O estilo brasileiro de administrar: sumário de um modelo de ação cultural brasileiro com base na gestão empresarial. In: Motta, F. C. P. Caldas, M. P. Cultura organizacional e cultura brasileira (pp. 55-69). São Paulo: Atlas.

Quiñones, P., Cantera, L. M., Moré, C. L. O. O. (2013). La violencia relacional en contextos laborales que trabajan contra la violencia. In: Cantera, L. M., Pallarès, S., Selva, C. Del malestar al bienestar laboral (pp. 135-155). Barcelona: Amentia.

Salin, D. Hoel, H. Organizational Risk Factors of Workplace Bullying (2020). In: Einarsen, S., Hoel, H., Zapf, D., Cooper, C. L. (Orgs.). Bullying and Harassment in the Workplace. Theory, Research and Practice (pp. 305-330). 3rd ed. London: Taylor \& Francis. 
Silva, E. P., Heloani, J. R., Piolli, E. (2012). Autonomia controlada e adoecimento do professor. Revista Educação e Politicas em Debate, 2(2), 370-383. Recuperado de http://www.seer.ufu.br/index.php/revistaeducaopoliticas/a rticle/view/21901

Tolfo, S. R. Nunes, T. S. (2017). Serviço Público e Assédio Moral no Trabalho: paradoxos entre a racionalidade das regras e a informalidade. In: Gediel, J. A. P., Mello, L. E., Zanin, F. C., Silva, J. L. A. (Org.).Estratégias autoritárias do Estado empregador: assédio e resistências (pp. 155-174). 1. ed. Curitiba: Kaygangue.

Triviños, A. N. S. (1992). Introdução à pesquisa em ciências sociais. a pesquisa qualitativa em educação. São Paulo: Atlas. 